DOI: 10.23860/JMLE-2019-11-2-10

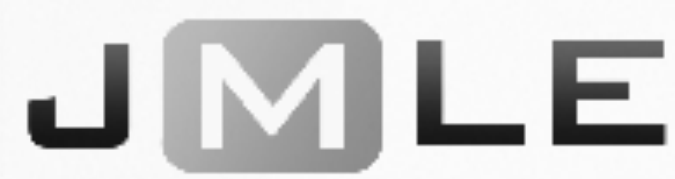

The National Association for Media Literacy Education's

Journal of Media Literacy Education, 11(2), 179 - 188

\title{
Real-Time Support: Using eCoaching to Increase Preservice Teachers' Confidence to Teach
}

\author{
Morgan V. Blanton, Aftynne E. Cheek \& Elizabeth Bellows \\ Appalachian State University, USA
}

\begin{abstract}
The role of teacher education preparation programs is to equip preservice teachers (PSTs) with the knowledge and skills to support the development of all students. To do this, university faculty must establish and monitor PSTs' progress toward quality standards for teaching. eCoaching is a professional learning strategy that provides real-time feedback to PSTs during instruction. In this article, the authors present an overview of $e$ Coaching logistics, a description of $e$ Coaching in action, and perceived impact of $e$ Coaching on PSTs.
\end{abstract}

Keywords: eCoaching, media literacy, teacher education, professional learning

As media progress and their uses change, the definition of media literacy still includes the ability to access, analyze, evaluate, create, communicate, and act using a variety of media forms (Aufderheide \& Firestone, 1992; National Association for Media Literacy Education [NAMLE], 2018). Media literacy helps students develop and apply critical thinking skills (e.g., analyzing, evaluating, and creating), and it can be used to help preservice teachers (PSTs) develop pedagogical excellence and technological proficiency (Domine, 2011). Although researchers recognize the critical need for media literacy in education, the definition of media literacy continues to evolve, and the need for full integration of media literacy education persists as societal needs change (Bulger \& Davison, 2018; Meehan, Ray, Walker, Wells, \& Schwarz, 2015).

The role of teacher education preparation programs is to equip PSTs with the knowledge and skills they need to become effective educators (Council for the Accreditation of Educator Preparation [CAEP], 2018), which is done through intentional coursework and clinical field experiences. Since media literacy permeates content and is not included as a specific strand in current curricula, university faculty and PSTs may not realize how the development of media literacy skills can help students critically engage with and progress towards mastery of their content learning objectives. With many programs offering specialized courses in media literacy as a separate class from content area methods classes, that perception 
may continue to spread among PSTs and teacher educators. eCoaching is one professional learning strategy that can be used to support PSTs' media literacy development and ability to infuse it into their future classroom practices. In this article, we describe $e$ Coaching and how it can be used as a tool for increasing confidence to teach, a sense of independence, and as an avenue for supporting media literacy development and integration.

\section{WHAT IS NEEDED FOR $e$ COACHING?}

$e$ Coaching can be defined as "a relationship in which one or more persons' effective teaching skills are intentionally and potentially enhanced through online or electronic interactions with another person" (Rock et al., 2014, p. 162). An $e$ Coach is someone (e.g., university supervisor, university faculty, mentor teacher, administrator) who provides feedback to another person through the use of technology or digital tools. When used, eCoaching blurs the traditional roles in teacher education (i.e., teacher, PST, university supervisor), which in turn facilitates a shared experience between the PST and the university supervisor (Zeichner, 2010). As a result, each individual becomes an equal participant in the learning process by fluctuation among the stages within a Gradual Release of Responsibility (GRR) model. Not only is eCoaching a means of communication via the use of digital tools, but university faculty can use $e$ Coaching as a vehicle for helping PSTs develop and improve their own media literacy skills, pedagogical practices, and content area knowledge.

There are multiple types of $e$ Coaching models in which technology is used to observe lessons and provide feedback and support. Some $e$ Coaching models utilize technology to record lessons first and then provide virtual feedback after the lesson has been taught (Bullock \& Ferrier-Kerr, 2014). However, the eCoaching model described in this article uses technology to provide feedback and support during the lesson in a real-time manner. To make it feasible to provide feedback during a lesson, the PST and $e$ Coach need to be able to communicate in a way that allows the $e$ Coach to 1) see the majority of the classroom, 2) hear the PST instructing students, and 3) speak to the PST so he/she can hear the eCoach's feedback while teaching.

To engage in eCoaching, technology such as a laptop, a bluetooth earbud, video conferencing software, and a web camera can be utilized to establish and maintain communication between the PST and $e$ Coach during the lesson (Figure 1). Video conferencing accounts such as Zoom (https://zoom.us/), Google Hangouts (https://hangouts.google.com), or Skype (https://skype.com) can be used for virtual communication. Additionally, a bluetooth earbud enables the PST to hear the $e$ Coach's feedback without distracting the PK-12 students. Finally, a wideangle web camera can be used to provide the $e$ Coach with a better view of the majority of the classroom. Having a wider view of the classroom enhances the $e$ Coach's ability to fully integrate into the lesson as a virtual co-teacher / supporter. 


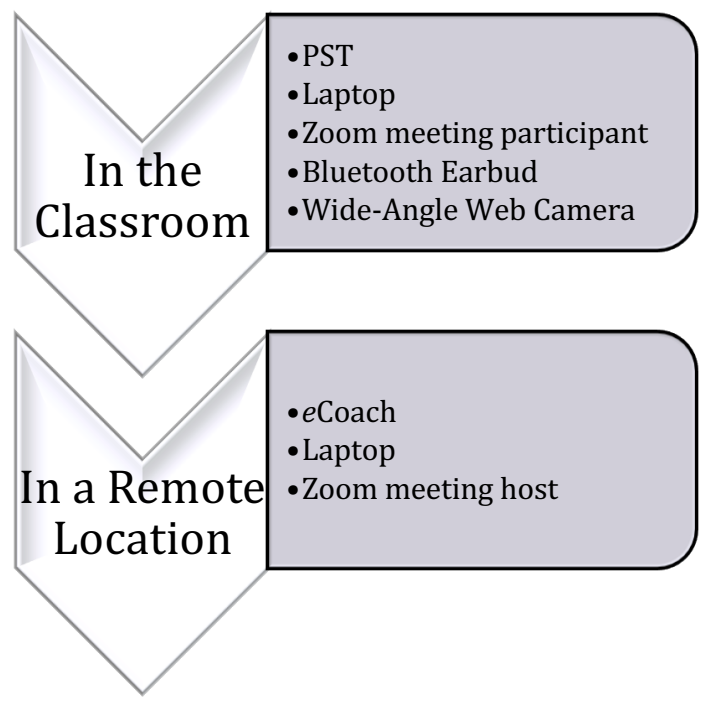

Figure 1. eCoaching materials.

During the eCoaching session, the $e$ Coach is fully vested in problemsolving and instructional decision-making. Since PSTs receive feedback immediately, they do not have to wait to implement the $e$ Coach's feedback, and they can see the impact it has on student learning. Three types of feedback are used to support the PST's professional learning during the eCoaching session: encouraging, corrective/instructive, and questioning (see Figure 2).

It is important to provide feedback to the PSTs that is both supportive and instructive. By using encouraging feedback, such as 'Nice job asking 'Why?' to deepen their thinking", the $e$ Coach is providing specific praise that will increase the likelihood the PST will want to replicate the noted teaching behavior. Research suggests providing encouraging feedback four times more than all of the other types of feedback combined (Rock et al., 2014).

On the other hand, providing corrective/instructive feedback in real-time allows the PST to not only pinpoint an opportunity for improvement but to also see the impact the change in teaching behavior has on the PST's effectiveness. It can be difficult to recreate a scenario during a traditional post-observation conference in order to explain why the PST should have or could have done something differently; however, by providing corrective/instructive feedback in the moment, the PST can apply the feedback to the current situation and experience the results of the change immediately.

The last type of feedback to use during instruction is questioning. This type of feedback is often used when the eCoach wants to remind the PST of an instructional practice that he/she already knows. Questioning feedback is rhetorical in nature, not meant to be answered but intended to spark and idea or remind the PST of prior knowledge related to instructional practices. 


\section{Types of Feedback}

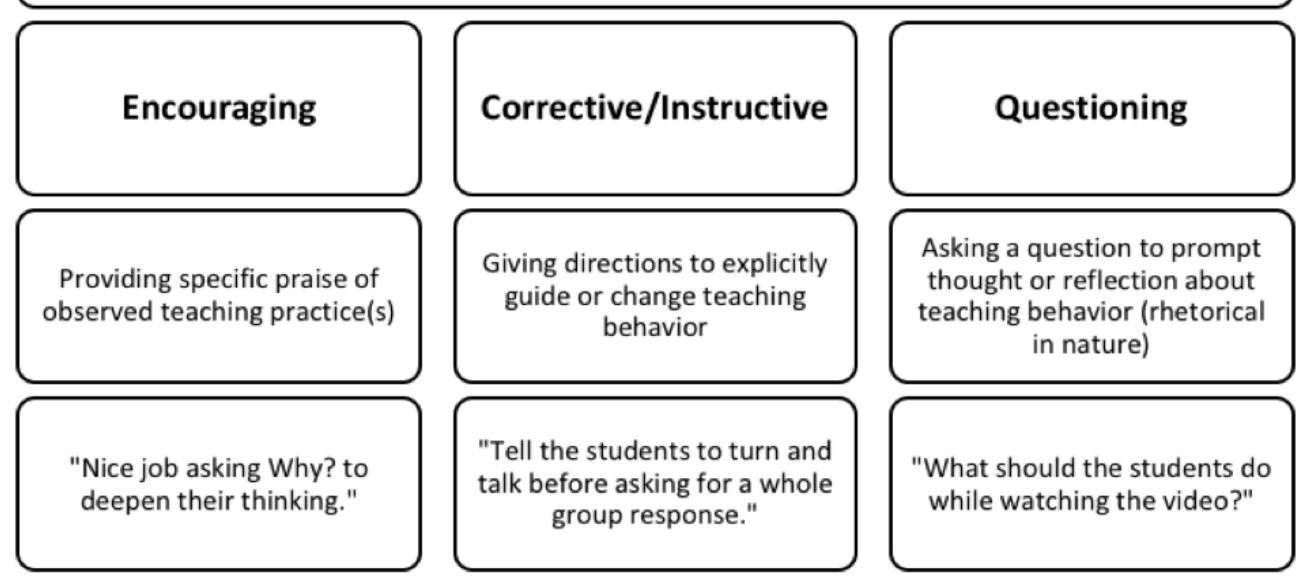

Figure 2. Types of feedback to use during eCoaching (Bellows, Cheek, \& Blanton, 2019).

\section{eCOACHING IN ACTION}

In order to demonstrate how eCoaching can be used to support a PST's development, we present a case of Ms. Brooks (cooperating teacher; high school social studies), Diana (PST; pseudonym), and the $e$ Coach (first author; university faculty) as an example of $e$ Coaching in action. The $e$ Coaching session took place during Diana's field experience in a local high school social studies classroom. Ms. Brooks observed the $e$ Coaching session taking place from the $e$ Coach's location across the hall. Through this case we contextualize $e$ Coaching logistics and discuss ways in which $e$ Coaching can be used to support a PST's growth and development during early field experience.

\section{Preparation and Practice}

First, Diana and the $e$ Coach engaged in a practice session during one of her university methods course class sessions. Diana wanted to receive $e$ Coaching to simulate what she would experience when she later taught a lesson to high schoolers. To practice, Diana engaged in microteaching as part of the requirements in her social studies methods course. She planned and taught a lesson to a small group of her peers. After the practice session, Diana debriefed her experience with the $e$ Coach and her university professor (third author). They discussed initial reactions, audio issues, and feedback timing in preparation for the eCoaching session in the high school classroom later on.

\section{Set-up and Implementation}

Now that Diana knew what to expect, she indicated that she was ready to try it during her field experience teaching. Before the class began, Diana connected a web camera to the laptop and positioned it in a corner of the classroom that would 
provide the $e$ Coach with the best view of the lesson. The wide-angle web camera allowed the $e$ Coach to view more of the room than a standard web camera or the integrated camera in most laptops can provide. Diana also wore a bluetooth earbud that had been paired with the laptop's audio. She wore a bluetooth earbud so she could hear the $e$ Coach's feedback during the lesson without disturbing students. The bluetooth earbud also served as a microphone so the $e$ Coach could hear Diana's voice clearly. From a classroom across the hall, the $e$ Coach initiated a Zoom video conference session with Diana and used her laptop's microphone to talk to Diana during the lesson. The $e$ Coach also muted her side of the Zoom video footage so students could only see her profile picture on Diana's laptop instead of the $e$ Coach's live feed. By muting her side of the video, the $e$ Coach reduced potential distractions for the students.

\section{The $e$ Coaching Session}

For the $e$ Coaching session, Diana planned a lesson about the New Deal during Franklin D. Roosevelt's presidency. She planned this lesson with guidance and feedback from Ms. Brooks and her university professor. Her lesson included instructional strategies such as interactive lecture, small group work, and studentled discussion. She also created curiosity about the topic by engaging the students in a game that allowed them to think critically while moving about the room. Following the game, Diana provided background information using interactive lecture as her primary instructional strategy and ended the lesson with small group research and presentations.

It is important to note that $e$ Coaching can occur during any type of instruction including teacher-led whole group discussions/lectures, small group collaborative assignments, and even during one-on-one conferencing. During the lesson, the $e$ Coach provided encouraging and instructive/corrective to Diana while she was teaching. Feedback focused on classroom management and instructional strategies. When Diana used a particular instructional strategy and she received praise specific to the use of that strategy, she quickly reflected on the $e$ Coach's comment, and her internal dialogue prompted her to want to continue using this strategy. When the $e$ Coach provided instructive feedback, Diana either used it right away or waited until a logical time during the lesson to give it a try. Sometimes Diana said or did exactly what the eCoach suggested, and other times she implemented the feedback by making it her own and modifying it slightly to fit her teaching style. The $e$ Coaching session was ninety minutes in length, corresponding to the time allotted for the fourth period class schedule.

\section{Debriefing the $e$ Coaching Session}

After the $e$ Coaching session, Diana, Ms. Brooks, the university professor, and the $e$ Coach debriefed the experience to learn more about their perceptions of $e$ Coaching as a professional learning strategy for PSTs. Ms. Brooks noted that the $e$ Coach was engaged in the lesson in a co-teacher role via the use of bluetooth and video conferencing technology. By using technology to communicate with Diana, the $e$ Coach was able to guide the PST and gradually give her more teaching responsibility while also providing highly individualized feedback and support. 
Diana mentioned that it was not awkward after the first few minutes and she said the feedback she received during the $e$ Coaching session was helpful, supportive, and encouraging.

\section{DISCUSSION}

Through the use of $e$ Coaching, the integral support that is provided during initial teaching episodes facilitates PSTs' knowledge acquisition and transfer into classroom practice. Thus, $e$ Coaching serves as a media literacy tool that university supervisors can use to help PSTs develop and apply critical thinking skills. Whether it is helping PSTs facilitate class discussions about propaganda techniques used during the New Deal Era or supporting the PST while he/she learns to model critical consumption of all media, eCoaching provides added scaffolding that can help PSTs transfer their knowledge and skills. Gretter and Yadav (2018) suggest that PSTs need university educators to model and teach media and information literacy to best prepare future teachers to integrate it into their instruction. $e$ Coaching could be a solution for this perceived deficit in our teacher education programs by taking advantage of technology that allows us to guide their critical thinking and pedagogical practices during early field experiences.

In addition to improving instructional practices, initial findings from ongoing qualitative research indicate $e$ Coaching also increases PSTs' confidence to teach (Bellows et al., 2019). While receiving virtual support from the $e$ Coach located outside of the classroom (e.g., across the hall, in another building, in another town), the PST has the opportunity to be "alone" in the classroom and experience what it feels like to be responsible for student learning while also receiving feedback and support from an experienced teacher. This "supported virtual independence" has been noted to have a positive impact on teaching confidence (Bellows et al., 2019).

\section{$e$ Coaching within the Gradual Release of Responsibility Model}

Throughout early field experiences prior to student teaching, university faculty in partnership with local mentor teachers have provided varying levels of scaffolding to PSTs as they improve their skills. As a goal of teacher education programs, student teaching is a time when PSTs should progress towards feeling confident to plan and deliver instruction independently. The GRR model is often used as a way to increase student responsibility for learning while allowing the instructor to adjust levels of support based on a PST's needs.

The GRR model was coined in the early 1980s and is still relevant to educational practices today (Cimino, 2018; Fisher \& Frey, 2013; Pearson \& Gallagher, 1983). There are four steps in the GRR instructional model: focused instruction, guided instruction, collaborative learning, and independent learning. The model suggests that students learn best when given the opportunity to interact with each other and when cognitive responsibility for learning is gradually shifted from the teacher to the student. Though initially used as a model for literacy instruction, this progression is used in many instructional settings including teacher education programs, especially during the field experience. 
eCoaching blurs the lines between the guided instruction, collaborative learning, and independent learning steps found within the GRR model (Figure 3). Fluctuating during the lesson between providing feedback (guided instruction), collaborative problem-solving (collaborative learning), and independent lesson facilitation (independent learning), eCoaching is a unique strategy for supporting PSTs through the GRR model as part of media literacy and teacher education programs.

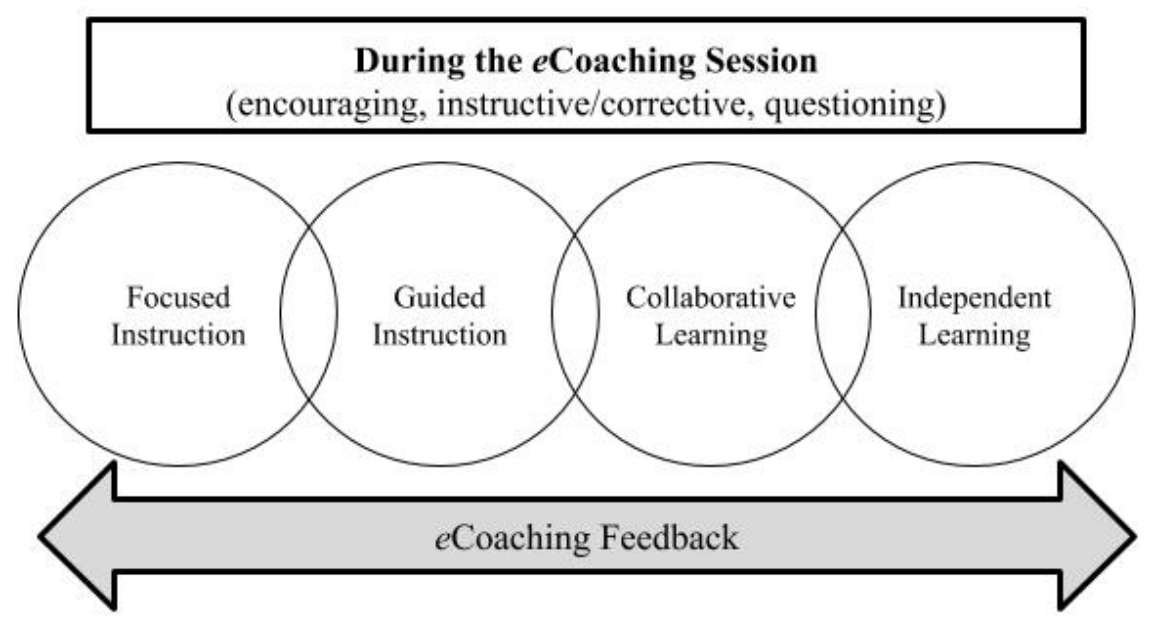

Figure 3. The gradual release of responsibility model through $e$ Coaching.

This GRR model gave Diana increased support and feedback while also increasing her sense of independence. The fluid nature of $e$ Coaching and the ways in which the $e$ Coach can move seamlessly between the GRR stages of instruction allowed the $e$ Coaching session to be personalized for the PST and her unique needs. To further support Gretter and Yadav's (2018) conclusions, we suggest that $e$ Coaching could be an effective way to increase PSTs' confidence to teach media literacy in their future classrooms.

\section{Perceptions of $\boldsymbol{e}$ Coaching as a Professional Learning Strategy}

Diana communicated positive perceptions of $e$ Coaching as a professional learning strategy. After the practice session, she reported that she thought wearing a bluetooth and getting feedback while teaching would be awkward but realized it was helpful instead. She noted that it was "weird" initially but when the eCoach started talking she quickly became used to it. She also said that it was helpful because she could "adjust on the spot as opposed to messing up and not knowing when I messed up." As a result of $e$ Coaching, Diana felt more supported through immediate feedback.

Specifically, during a coaching session, Diana was unsure how to use questioning to facilitate critical thinking about a topic. At times during the lesson, she struggled to lead students to support their ideas with specific reasons. The $e$ Coach provided brief suggestions to her via bluetooth so Diana could lead the discussion using questions that fostered deeper thinking. For example, the $e$ Coach 
suggested, "Ask him to tell you why," to help the PST engage the student in deeper thinking. By guiding Diana to ask more "why" questions, she learned how to probe students to consider evidence and take a stand. By the end of the lesson, Diana was initiating "why" questions on her own without prompting. At this point in the lesson, the $e$ Coach was providing encouraging feedback such as "Nice job asking why."

Diana also said that the support she received during the sessions via bluetooth made her feel more confident in her ability to teach. She said that if she felt unsure, she knew she had someone there to help her. Paradoxically, Diana felt a strong feeling of immediate support while at the same time feeling completely independent for the first time, given this was the first opportunity Diana had to physically be in the classroom with only her students. She was without the physical presence of her mentor yet reassuringly connected to her. Both Diana and Ms. Brooks reported that they felt the $e$ Coaching model was a better way to prepare PSTs for student teaching.

\section{Conclusion}

We propose $e$ Coaching as a professional learning strategy that can be used during early field experiences to build confidence and increase independence as they learn to teach their content and facilitate critical thinking and media literacy skills in their own classrooms. The nature of $e$ Coaching is fluid, and it fuses well with a GRR model. As mentor teachers gradually release responsibilities of planning and teaching during their field experiences, we argue that PST's perceived independence might be greater when using $e$ Coaching than it would be otherwise.

This "supported virtual independence" led to increased confidence to teach in Diana's case. We attribute that not only to the fluid nature of GRR, but also because the PST received immediate feedback, including specific praise, while she was teaching. In a sense, the $e$ Coach helped increase Diana's confidence by building the momentum for her to keep using particular strategies, which will aid in her development of effective teaching habits in the future.

In conclusion, we suggest a change to current field support practices to include $e$ Coaching. Based on these findings, $e$ Coaching can build confidence and independence prior to student teaching. Furthermore, through the unique way $e$ Coaching integrates a fluid implementation of the gradual release of responsibility instructional model, $e$ Coaches can also use this professional learning strategy as a means to help PSTs find ways to teach and model media literacy skills as an integrated part of their content learning objectives in a seamless and meaningful manner. We know that eCoaching increases confidence to teach (Bellows et al., 2019), and we agree that PSTs need to see instructional strategies modeled in order to gain knowledge and skills needed to teach effectively (Gretter \& Yadav, 2018). Research indicates that confidence has a positive impact on student achievement (Hattie, 2012; Khan, 2011; Ashton, 1984). Why not set our PSTs up for success when they enter public school classrooms by using a professional learning tool at the university level that will ultimately improve PK-12 student outcomes? 


\section{REFERENCES}

Aufderheide, P., \& Firestone, C. M. (1992). Media literacy: A report of the National Leadership Conference on Media Literacy. Queenstown, MD: Aspen Institute.

Ashton, P. (1984). Teacher efficacy: A motivational paradigm for effective teacher education. Journal for Teacher Education, 35(5), 28-32.

Bellows, E., Cheek, A., \& Blanton, M. (2019). E-Coaching to support universitypublic school partnerships: Disrupting power dynamics in teacher education. In T. Heafner \& R. Hartshorne (Eds.), Handbook of research on emerging practices and methods for K-12 online and blended learning (pp. 333-354). Hershey, PA: IGI Global.

Bulger, M., \& Davison, P. (2018). The promises, challenges and futures of media literacy. Journal of Media Literacy Education, 10(1), 1-21.

Bullock, T., \& Ferrier-Kerr, J. (2014). The potential of eCoaching and eMentoring: Making a case for the introduction of sustainable eCoaching and eMentoring programmes in New Zealand schools. New Zealand Journal of Teachers' Work, 11(1), 77-92.

Council for the Accreditation of Educator Preparation. (2018). The CAEP standards. Retrieved from http://www.caepnet.org/stan-dards/introduction

Cimino, M. (2018). Synthesizing the flipped classroom with the gradual release of responsibility model. Australian Educational Leader, 40(1), 40-42.

Domine, V. (2011). Building 21st century teachers: An intentional pedagogy of media literacy education. Action in Teacher Education, 33(2), 104-205. doi:10.1080/01626620.2011.569457

Gretter, S., \& Yadav, A. (2018). What do preservice teachers think about teaching media literacy? An exploratory study using the theory of planned behavior. Journal of Media Literacy Education, 10(1), 104-123.

Fisher, D., \& Frey, N. (2013). Engaging the adolescent learner: Gradual release of responsibility instructional framework. Newark, DE: International Reading Association.

Hattie, J. (2012). Visible learning for teachers: Maximizing impact on learning. New York: Routledge/Taylor \& Francis Group.

Khan, A. S. (2011). Teacher Efficacy - A tool to enhance academic achievement of secondary schools. Language in India, 11(6), 235-247.

Meehan, J., Ray, B., Walker, A., Wells, S., \& Schwarz, G. (2015). Media literacy in teacher education: A good fit across the curriculum. Journal of Media Literacy Education, 7(2), 81-86.

National Association for Media Literacy Education (NAMLE). (2018). Media literacy defined. Retrieved from https://namle.net/publications/medialiteracy-definitions/

Pearson, P. D., \& Gallagher, M. C. (1983). The instruction of reading comprehension. Contemporary Educational Psychology, 8(3), 317-344.

Rock, M. L., Schumacker, R., Gregg, M., Howard, P. W., Gable, R. A., \& Zigmond, N. (2014). How are they now? Longer term effects of eCoaching through online bug- in-ear technology. Teacher Education and 
Special Education, 37(2), 161-181.

Zeichner, K. (2010). Rethinking the connections between campus courses and field experiences in college- and university-based teacher education. Journal of Teacher Education, 61(1), 89-99. 